\title{
U.S. Geological Survey Assessment of Reserve Growth Outside of the United States
}

Scientific Investigations Report 2015-5091 



\section{U.S. Geological Survey Assessment of Reserve Growth Outside of the United States}

By Timothy R. Klett, Troy A. Cook, Ronald R. Charpentier, Marilyn E. Tennyson, and Phuong A. Le

Scientific Investigations Report 2015-5091 


\title{
U.S. Department of the Interior SALLY JEWELL, Secretary
}

\section{U.S. Geological Survey \\ Suzette M. Kimball, Acting Director}

\author{
U.S. Geological Survey, Reston, Virginia: 2015
}

For more information on the USGS - the Federal source for science about the Earth, its natural and living resources, natural hazards, and the environment—visit http://www.usgs.gov or call 1-888-ASK-USGS.

For an overview of USGS information products, including maps, imagery, and publications, visit http://www.usgs.gov/pubprod/.

Any use of trade, firm, or product names is for descriptive purposes only and does not imply endorsement by the U.S. Government.

Although this information product, for the most part, is in the public domain, it also may contain copyrighted materials as noted in the text. Permission to reproduce copyrighted items must be secured from the copyright owner.

Suggested citation:

Klett, T.R., Cook, T.A., Charpentier, R.R., Tennyson, M.E., and Le, P.A., 2015, U.S. Geological Survey assessment of reserve growth outside of the United States: U.S. Geological Survey Scientific Investigations Report 2015-5091, 13 p., http://dx.doi.org/10.3133/sir20155091.

ISSN 2328-0328 (online) 


\section{Contents}

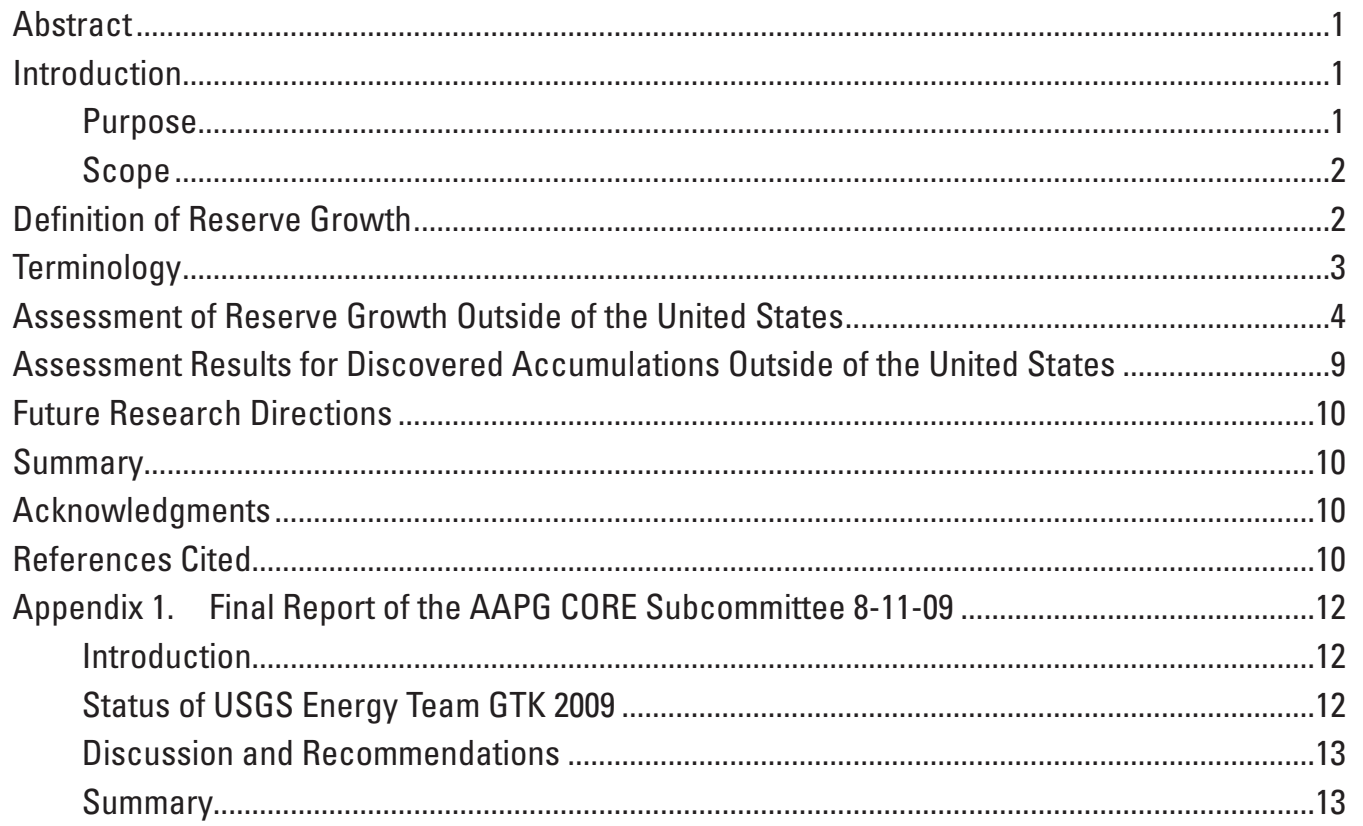

\section{Figures}

1. Diagram showing field-development activities that can increase reserves estimates (reserve growth)

2. Diagram showing the differences between conventional and unconventional accumulations. Conventional accumulations contain oil and(or) gas that are buoyant upon a water column.

3. Bar chart showing the range of uncertainty of original oil in-place volumes for the 68 large U.S. oil accumulations that were individually analyzed in this study ..................7

4. Bar charts showing the distribution of recovery factors used to calculate reserve growth in accumulations outside the United States...

5. Circular (pie) diagrams showing crude oil and natural gas endowment outside of the United States.

\section{Tables}

1. Table of discovered, conventional accumulations in the U.S. that were individually analyzed in this study, estimated ranges of original in-place volumes (lognormal distribution), estimated ranges of recovery factors (triangular distribution), and reported or estimated coproduct ratios (point values).....

2. Table of assessment results for discovered accumulations outside of the United States (technically recoverable, conventional petroleum resources) 


\section{Conversion Factors}

\begin{tabular}{lll}
\hline \multicolumn{1}{c}{ Multiply } & By & \multicolumn{1}{c}{ To obtain } \\
\hline barrel $(\mathrm{bbl})$ & 0.1590 & cubic meter $\left(\mathrm{m}^{3}\right)$ \\
barrel $(\mathrm{bbl})$ & 0.136 & metric ton $(\mathrm{MT})$, average gravity \\
cubic feet $\left(\mathrm{ft}^{3}\right)$ & 0.02382 & cubic meter $\left(\mathrm{m}^{3}\right)$ \\
cubic meter $\left(\mathrm{m}^{3}\right)$ & 35.3147 & cubic feet $\left(\mathrm{ft}^{3}\right)$ \\
metric ton $(\mathrm{MT})$ & 7.33 & barrel $(\mathrm{bbl})$, average gravity \\
\hline
\end{tabular}




\title{
U.S. Geological Survey Assessment of Reserve Growth Outside of the United States
}

\author{
By Timothy R. Klett, Troy A. Cook, Ronald R. Charpentier, Marilyn E. Tennyson, and Phuong A. Le
}

\section{Abstract}

The U.S. Geological Survey estimated volumes of potential additions to oil and gas reserves for the United States by reserve growth in discovered accumulations. These volumes were derived by using a new methodology developed by the U.S. Geological Survey and reviewed by the American Association of Petroleum Geologists Committee on Resource Evaluation. This methodology was used to assess reserve growth in individual accumulations (reservoirs, groups of reservoirs, or fields). Selected, large, well-studied, conventional accumulations in the United States that are estimated to contribute most to reserve growth were assessed using analysis of geology and engineering practices. Potential additions to oil and gas reserves for large, discovered, conventional accumulations outside of the United States due to reserve growth were assessed using the U.S. accumulations as analogs. Potential oil and gas volumes were assumed to be added to proven plus probable reserves.

The U.S. Geological Survey estimated volumes of technically recoverable, conventional petroleum resources resulting from reserve growth for discovered fields outside the United States that have reported in-place oil and gas volumes of 500 million barrels of oil equivalent or greater. The mean volumes of reserve growth were estimated at 665 billion barrels of crude oil; 1,429 trillion cubic feet of natural gas; and 16 billion barrels of natural gas liquids. These volumes constitute a significant portion of the world's oil and gas resources and represent the potential future growth of current global reserves over time based on better assessment methodology, new technologies, and greater understanding of reservoirs.

\section{Introduction}

\section{Purpose}

The U.S. Geological Survey (USGS) assesses undiscovered conventional and unconventional, technically recoverable oil and gas resources of the United States (excluding Federal Outer Continental Shelf) and the world.
The Bureau of Ocean Energy Management (BOEM) is responsible for the assessment of oil and gas resources of the Federal Outer Continental Shelf. Reserves in discovered conventional accumulations can sometimes increase because of delineation of additional in-place petroleum volumes, improved recovery efficiency, and revisions from recalculation of viable reserves in dynamically changing economic, operating, and regulatory/political conditions (fig. 1). The USGS considers additions to reserves as a resource and, therefore, assesses reserve growth. This report describes the USGS methodology and assessment process for estimating volumes of reserve growth, as well as estimates of reserve growth in accumulations outside of the United States.

The estimates presented in this report were derived using a new method to assess reserve growth in discovered conventional accumulations developed by the USGS (Klett and others, 2011). This methodology is different from that used in past USGS assessments (Cook, 2013). Estimates of the distributions of in-place oil and gas and recovery factors in large, well-studied, U.S. accumulations (individual reservoirs, groups of reservoirs, or fields) were used as analogs for the assessment of accumulations outside of the United States. The USGS assessment method was reviewed by the Subcommittee on Growth-to-Known Reserves of the American Association of Petroleum Geologists Committee on Resource Evaluation of the (AAPG CORE) in March 2008 (Appendix 1).

Identified unconventional (continuous) oil and gas accumulations, such as shale gas, tight gas, tight oil, and tar sands, were excluded from this assessment of reserve growth. The USGS assesses unconventional, technically recoverable oil and gas resources using a methodology that is different from that used to assess conventional resources (Charpentier and Cook, 2011). This methodology to assess unconventional resources includes potential additions to reserves.

In addition to estimating potential additions to reserves in discovered accumulations by reserve growth, the USGS makes estimates of the potential fully developed (grown) sizes of undiscovered conventional accumulations to aid in the estimation of undiscovered oil and gas resources. 


\section{Scope}

The recently developed USGS method to assess reserve growth was used to estimate technically recoverable crude oil and natural gas volumes that have the potential to be added to reserves in discovered conventional accumulations under proven technology currently in practice within the trend or play, or which can reasonably be extrapolated from geologically similar trends or plays. These estimates do not assume or include estimates based on the application of speculative future technologies. The assessment methodology estimates future potential additions to reserves using current technology, but not necessarily current economics. No time period was assumed for the estimated reserve growth volumes in this report to take place.

Reserve growth was assessed for oil in oil accumulations and was assessed for nonassociated gas in gas accumulations. Reserve growth of coproducts (associated/dissolved gas and natural gas liquids in oil accumulations, and total liquids in gas accumulations) was calculated based on the volumetric coproduct ratios with the primary commodity (oil or gas) within the accumulation. Only crude oil and nonassociated natural gas that flows to a wellbore (either naturally or upon various production operations) were assessed directly.
Associated and dissolved natural gas and natural gas liquids were assumed to grow by the same ratio as the primary commodity (gas in gas accumulations, oil in oil accumulations).

No attempt was made to estimate economically recoverable resources. Costs and economics of drilling and production operations to promote reserve growth can be analyzed and modeled to provide information on current and future development and production operations; however, these cost data were not included in this study.

\section{Definition of Reserve Growth}

Reserve growth is the increase in estimated volumes of oil and natural gas that might be recovered from existing fields and reservoirs through time. Most reserve growth results from delineation of new reservoirs, field extensions, or enhanced recovery techniques that improve efficiency; or from recalculation of reserves due to changing economic and operating conditions (fig. 1). Many accumulations show no growth of reserves and many reserve volumes shrink, however. The term "reserve growth" as used here, is synonymous with "growthto-known," "reserve appreciation," "ultimate recovery appreciation," "field growth," or "reservoir growth," among others.

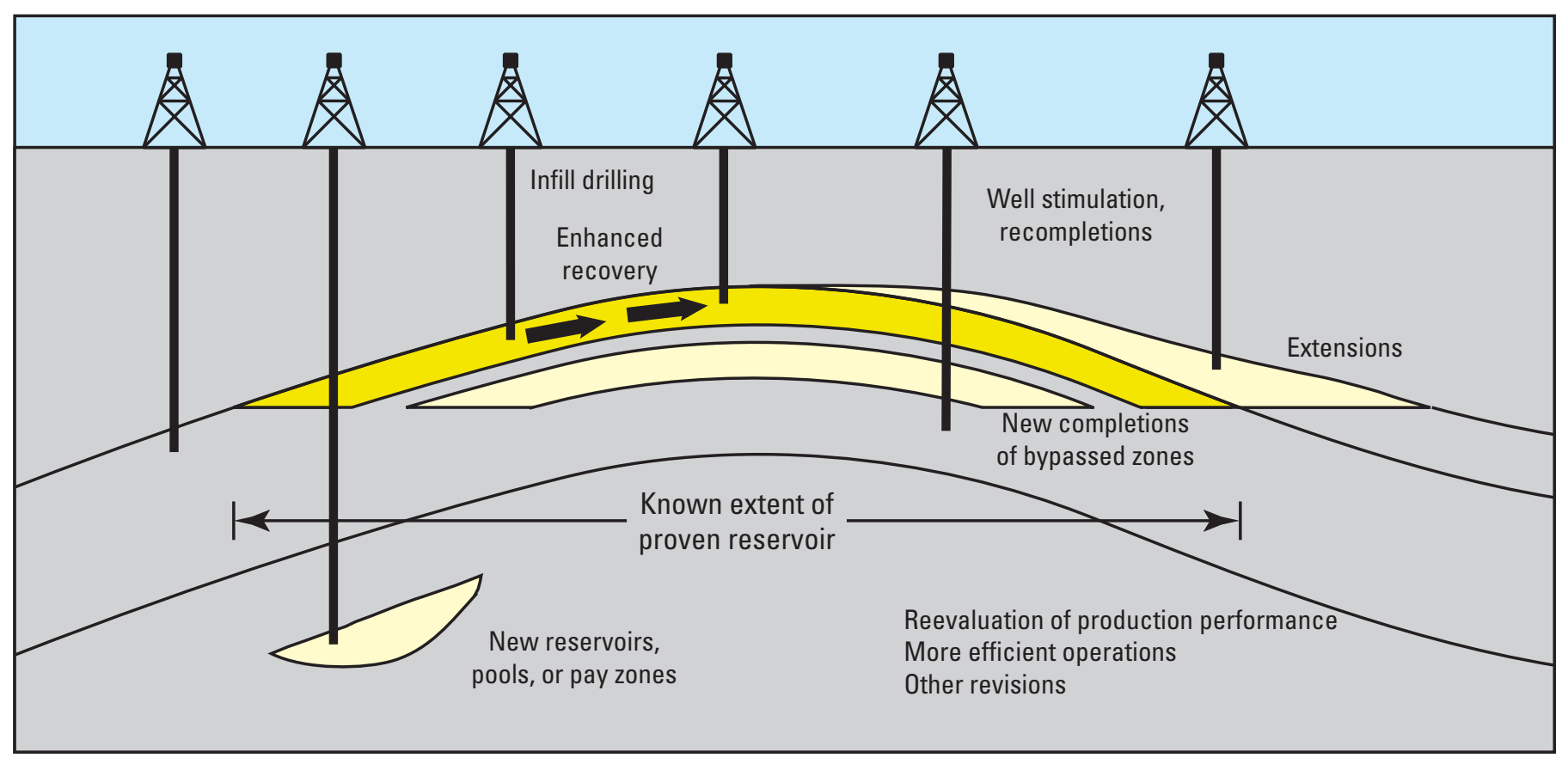

Figure 1. Diagram showing field-development activities that can increase reserves estimates (reserve growth). Reserve growth is defined as increases in successive estimates of recoverable quantities of crude oil, natural gas, and natural gas liquids in discovered conventional accumulations. Reserve growth can be grouped into three activities: (1) delineation of additional in-place petroleum volumes, which increases the degree of geologic assurance (for example, infill drilling; new reservoirs, pools, or pay zones; extensions); (2) improved recovery efficiency, which increases the degree of technological feasibility (for example, enhanced recovery, well stimulation, recompletions, new completions of bypassed zones); and (3) revisions resulting from recalculation of viable reserves in dynamically changing economic, operating, and regulatory/political conditions, which increases the degree of economic feasibility (for example, reevalution of production performance, more efficient operations) (Klett, 2005). 


\section{Terminology}

Several technical terms are used in this report to describe reserve growth. These terms and their definitions according to the USGS are presented below.

Accumulation is a deposit of crude oil, natural gas, natural gas condensate, and(or) natural gas liquids (NGL) within a field, or reservoir(s) within a field. An accumulation might equate to a single reservoir, group of reservoirs, or an entire field.

Oil accumulations are defined by the ratio of gas to oil as containing less than 20,000 cubic feet of gas per barrel of oil.

Gas accumulations are defined by the ratio of gas to oil as containing 20,000 or more cubic feet of gas per barrel of oil. Gas in this type of accumulation is assumed to be nonassociated gas rather than associated with or dissolved in an oil accumulation.

Conventional accumulations contain oil and(or) gas that are buoyant upon a water column. Conventional accumulations have discrete boundaries typically bounded by dry holes, and usually have relatively good reservoir properties (porosity and permeability) (fig. 2).

Unconventional accumulations contain oil and(or) gas that are not buoyant upon a water column. Unconventional accumulations are regional in extent and typically have relatively poor reservoir properties whereby stimulation is required for production (fig. 2).
Resource is a concentration of petroleum in or on the earth's crust, some of which is potentially economically extractable.

Original in-place volume is the volume of crude oil, natural gas, and NGL originally present in the reservoir(s) whether or not they are technically or economically recoverable.

Recoverability or recovery efficiency is the estimated fraction (known as recovery factor) of the original in-place volume that can be extracted.

Cumulative production is the total volume of petroleum that has been extracted.

Remaining reserves are estimated volumes of petroleum that are expected to be commercially recovered, as of a specified date (exclusive of production). Remaining reserves are commonly classified as proved, proved-plus-probable, and proved-plus-probable-plus-possible. Reserves are resources, but resources are not necessarily reserves.

Recoverable volume (reported volumes that are also called field size or accumulation size) is the sum of cumulative production and remaining reserves. Recoverable volume can also be defined as cumulative volumes of oil, gas, and natural gas liquids that might be extracted with known technologies by the end of the development and production process. Reported recoverable volumes are called known recoverable volumes in this paper.

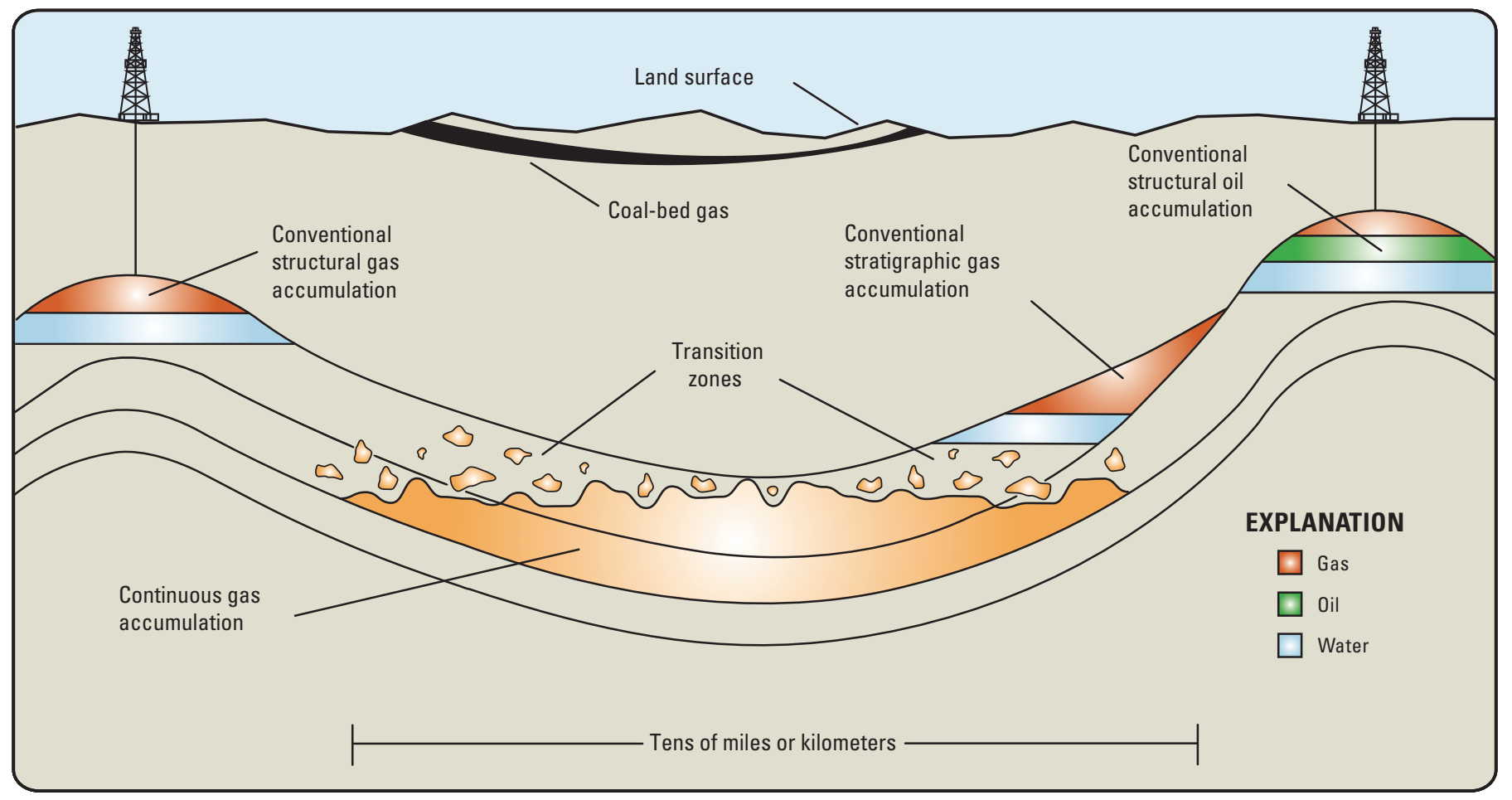

Figure 2. Diagram showing the differences between conventional and unconventional accumulations. Conventional accumulations contain oil and(or) gas that are buoyant upon a water column. Conventional accumulations have discrete boundaries typically bounded by dry holes, and usually have good reservoir properties (porosity and permeability). Unconventional accumulations contain oil and(or) gas that are not buoyant upon a water column. Unconventional accumulations are regional in extent and typically have poor reservoir properties whereby stimulation is required for production. Figure modified by Schenk and Pollastro (2002) from Schmoker (1996). 
Assessment of Reserve Growth Outside of the United States

The USGS method for calculating reserve growth uses reported estimates of original in-place volumes and recoverability (recovery factors) of accumulations that were individually analyzed. Volumetric data and recovery factors for accumulations outside of the United States are reported for fields as a whole and as single estimates for any given year. Original in-place volumes and recovery factors for accumulations outside the United States were taken from the proprietary IHS (2009) International Exploration and Production Database.

Because recoverable volumes for individual reservoirs were not reported for many fields outside of the United States, the individual accumulation analysis was not used. Data acquired from individually analyzed U.S. accumulations were used as analogs in this study. Studies of 68 large, well-studied oil accumulations and two large, well-studied gas accumulations in the United States provided probability distributions for uncertainty of original in-place volumes and recovery factors for non-U.S. accumulations (table 1).
The uncertainty ranges of in-place volumes of individually analyzed U.S. oil or gas accumulations were applied to the in-place volumes of oil and gas fields outside of the United States. The probability distributions of recovery factors of the individually analyzed accumulations were used in the calculation of reserve growth. Large oil and gas accumulations, reported at a field level by IHS, are more likely to experience reserve growth, and their respective in-place volumes should be relatively well reported and accurate. Only fields in the IHS (2009) international database having original in-place volumes of 0.5 billion barrels of oil (BBO) or more of oil in oil fields, or 3 trillion cubic feet of gas (TCFG) or more of gas in gas fields were used for this assessment. The in-place and recovery factor distributions were statistically combined using a Monte Carlo simulation for 50,000 iterations. Estimates of future reserve growth are relative to the sum of cumulative production and proven-plus-probable reserves, reported as recoverable volumes, in the database. The results of the Monte Carlo simulation were then aggregated to provide an approximation of reserve growth for the world.

The range of uncertainty of original oil in-place volumes for U.S. oil accumulations (fig. 3), normalized to a central tendency of 1.0, was applied to reported original in-place

Table 1. Table of discovered, conventional accumulations in the U.S. that were individually analyzed in this study, estimated ranges of original in-place volumes (lognormal distribution), estimated ranges of recovery factors (triangular distribution), and reported or estimated coproduct ratios (point values).

[MMBO, million barrels of oil; BCFG, billion cubic feet of gas; $\mathrm{CFG} / \mathrm{BO}$, cubic feet of gas per barrel of oil; NGL, natural gas liquids; BO/MMCFG, barrels of oil per million cubic feet of gas; Min., minimum; Med., median; Max., maximum]

\begin{tabular}{|c|c|c|c|c|c|c|c|c|}
\hline \multirow{2}{*}{ Oil in oil accumulations } & \multicolumn{3}{|c|}{$\begin{array}{c}\text { Estimated original } \\
\text { in-place hydrocarbons, MМВ0 }\end{array}$} & \multicolumn{3}{|c|}{ Estimated recovery factor } & \multirow{2}{*}{$\begin{array}{l}\text { Gas/oil } \\
\text { CFG/BO }\end{array}$} & \multirow{2}{*}{$\begin{array}{l}\text { NGL/gas } \\
\text { BO/MMCFG }\end{array}$} \\
\hline & Min. & Med. & Max. & Min. & Mode & Max. & & \\
\hline Alpine, all reservoirs & 950 & 1,000 & 1,200 & 0.40 & 0.45 & 0.55 & 1,021 & 75.0 \\
\hline Brea-Olinda, all reservoirs & 1,200 & 1,600 & 2,400 & 0.35 & 0.40 & 0.45 & 1,129 & 118.4 \\
\hline Cymric Welport and McKittrick Front, pre-Monterey & 145 & 175 & 210 & 0.30 & 0.40 & 0.55 & 2,262 & 56.2 \\
\hline Cymric: Welport, Tulare & 550 & 700 & 1,000 & 0.55 & 0.65 & 0.85 & 51 & 67.6 \\
\hline Dominguez, all reservoirs & 1,000 & 1,200 & 1,450 & 0.35 & 0.40 & 0.50 & 1,461 & 69.4 \\
\hline Elk Hills, Stevens, Monterey, and older reservoirs & 2,300 & 2,700 & 3,500 & 0.35 & 0.40 & 0.50 & 3,128 & 78.7 \\
\hline Huntington Beach, all reservoirs & 3,250 & 3,500 & 6,000 & 0.35 & 0.40 & 0.55 & 747 & 53.3 \\
\hline Inglewood, all reservoirs & 1,000 & 1,400 & 2,500 & 0.40 & 0.45 & 0.55 & 681 & 41.0 \\
\hline Kern River, Kern River and Vedder & 3,400 & 3,600 & 4,200 & 0.70 & 0.75 & 0.85 & 4 & 67.6 \\
\hline West Sak, West Sak East & 7,000 & 9,000 & 15,000 & 0.10 & 0.20 & 0.50 & & \\
\hline West Sak, West Sak West & \multicolumn{8}{|c|}{ not quantitatively assessed } \\
\hline Kuparuk River, Kuparuk River & 5,100 & 6,000 & 7,000 & 0.50 & 0.60 & 0.70 & 6 & 188.5 \\
\hline
\end{tabular}


Table 1. Table of discovered, conventional accumulations in the U.S. that were individually analyzed in this study, estimated ranges of original in-place volumes (lognormal distribution), estimated ranges of recovery factors (triangular distribution), and reported or estimated coproduct ratios (point values).-Continued

[MMBO, million barrels of oil; BCFG, billion cubic feet of gas; $\mathrm{CFG} / \mathrm{BO}$, cubic feet of gas per barrel of oil; NGL, natural gas liquids; BO/MMCFG, barrels of oil per million cubic feet of gas; Min., minimum; Med., median; Max., maximum]

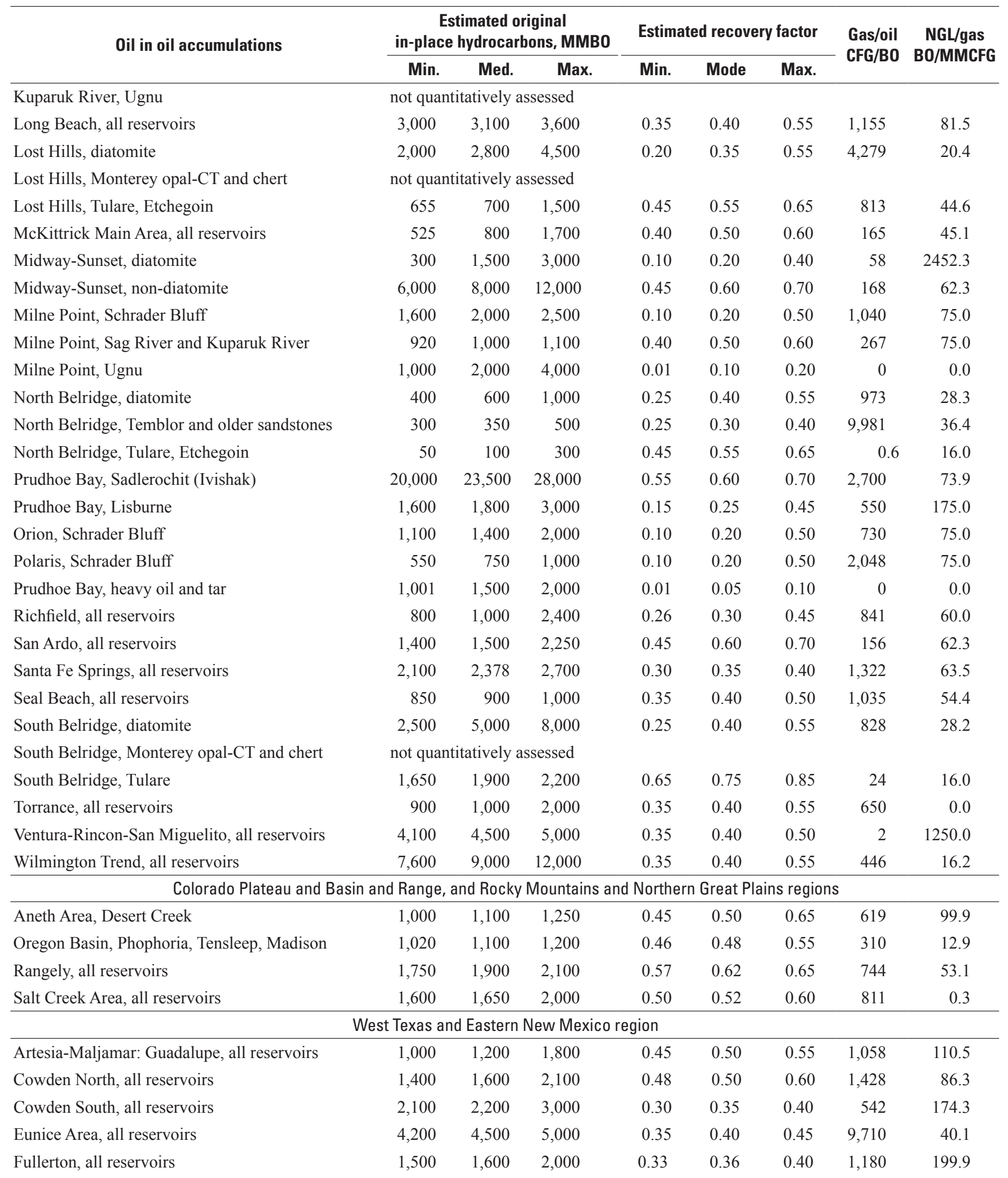


Table 1. Table of discovered, conventional accumulations in the U.S. that were individually analyzed in this study, estimated ranges of original in-place volumes (lognormal distribution), estimated ranges of recovery factors (triangular distribution), and reported or estimated coproduct ratios (point values). - Continued

[MMBO, million barrels of oil; BCFG, billion cubic feet of gas; CFG/BO, cubic feet of gas per barrel of oil; NGL, natural gas liquids; BO/MMCFG, barrels of oil per million cubic feet of gas; Min., minimum; Med., median; Max., maximum]

\begin{tabular}{|c|c|c|c|c|c|c|c|c|}
\hline \multirow{2}{*}{ Oil in oil accumulations } & \multicolumn{3}{|c|}{$\begin{array}{c}\text { Estimated original } \\
\text { in-place hydrocarbons, MМBO }\end{array}$} & \multicolumn{3}{|c|}{ Estimated recovery factor } & \multirow{2}{*}{$\begin{array}{l}\text { Gas/oil } \\
\text { CFG/BO }\end{array}$} & \multirow{2}{*}{$\begin{array}{l}\text { NGL/gas } \\
\text { BO/MMCFG }\end{array}$} \\
\hline & Min. & Med. & Max. & Min. & Mode & Max. & & \\
\hline Hobbs, all reservoirs & 800 & 1,000 & 1,300 & 0.50 & 0.55 & 0.60 & 1,906 & 90.9 \\
\hline Howard-Glasscock, all reservoirs & 1,500 & 1,600 & 1,800 & 0.35 & 0.38 & 0.50 & 125 & 0.3 \\
\hline Salt Creek (Permian Basin), all reservoirs & 680 & 700 & 730 & 0.60 & 0.63 & 0.65 & 670 & 199.6 \\
\hline Scurry, all reservoirs & 3,000 & 3,100 & 3,300 & 0.55 & 0.62 & 0.65 & 727 & 334.6 \\
\hline Seminole, all reservoirs & 1,250 & 1,300 & 1,400 & 0.55 & 0.60 & 0.65 & 987 & 129.7 \\
\hline Slaughter-Levelland, all reservoirs & 4,200 & 4,600 & 5,600 & 0.48 & 0.50 & 0.60 & 710 & 169.9 \\
\hline Wasson Area, San Andres-Glorieta & 4,410 & 4,500 & 4,600 & 0.58 & 0.60 & 0.63 & 924 & 136.1 \\
\hline Yates, all reservoirs & 4,000 & 4,300 & 5,000 & 0.40 & 0.45 & 0.55 & 86 & 186.0 \\
\hline \multicolumn{9}{|c|}{ Gulf Coast region } \\
\hline Conroe, all reservoirs & 1,350 & 1,400 & 1,600 & 0.55 & 0.60 & 0.65 & 1,894 & 49.7 \\
\hline East Texas, Woodbine & 7,000 & 7,100 & 7,500 & 0.78 & 0.80 & 0.85 & 263 & 450.7 \\
\hline Hawkins, all reservoirs & 1,300 & 1,350 & 1,500 & 0.70 & 0.72 & 0.75 & 662 & 139.4 \\
\hline \multicolumn{9}{|c|}{ Midcontinent and Eastern regions } \\
\hline Sho-Vel-Tum, all reservoirs & 3,550 & 3,600 & 4,000 & 0.50 & 0.52 & 0.60 & 348 & 2552.9 \\
\hline Gas in gas accumulations & \multicolumn{3}{|c|}{$\begin{array}{c}\text { Estimated original } \\
\text { in-place hydrocarbons, BCFG }\end{array}$} & \multicolumn{3}{|c|}{ Estimated recovery factor } & \multicolumn{2}{|r|}{$\begin{array}{l}\text { Liq/gas } \\
\text { BO/MMCFG }\end{array}$} \\
\hline
\end{tabular}

volumes for oil accumulations and for gas accumulations outside the United States. This distribution ranges from approximately 0.2 to 3.7 and has a mean value of 1.1. A value was randomly selected from this distribution during each Monte Carlo iteration and multiplied times the reported in-place volume of the field, resulting in a probability distribution for in-place volumes.

An empirical probability distribution of recovery factors of the 68 U.S. oil accumulations that were assessed by individual accumulation analysis was used as an analog to estimate recovery factors in oil fields outside the United States (fig. 4). This distribution ranges from approximately 0.01 to 0.85 and has a mean value of 0.46 . This distribution for U.S. accumulations was based on accumulations with a wide range of reservoirs, oil types, and degrees of development. A uniform probability distribution of gas recovery factors ranging from 0.7 to 0.9 was applied to gas fields outside of the United States. Reported recovery factors for gas fields outside of the United States varied widely, and only two U.S. gas accumulations have been individually analyzed.

Distributions of reserve-growth volumes were calculated for each of the 1,467 oil fields having 500 million barrels of oil equivalents (MMBOE) or more of original in-place oil and 347 of the gas fields having $500 \mathrm{MMBOE}$ or more of original in-place gas outside of the United States. Probability distributions of the original in-place volumes for each 
Normalized Uncertainty of Original Oil In-Place for Oil in Oil Accumulations

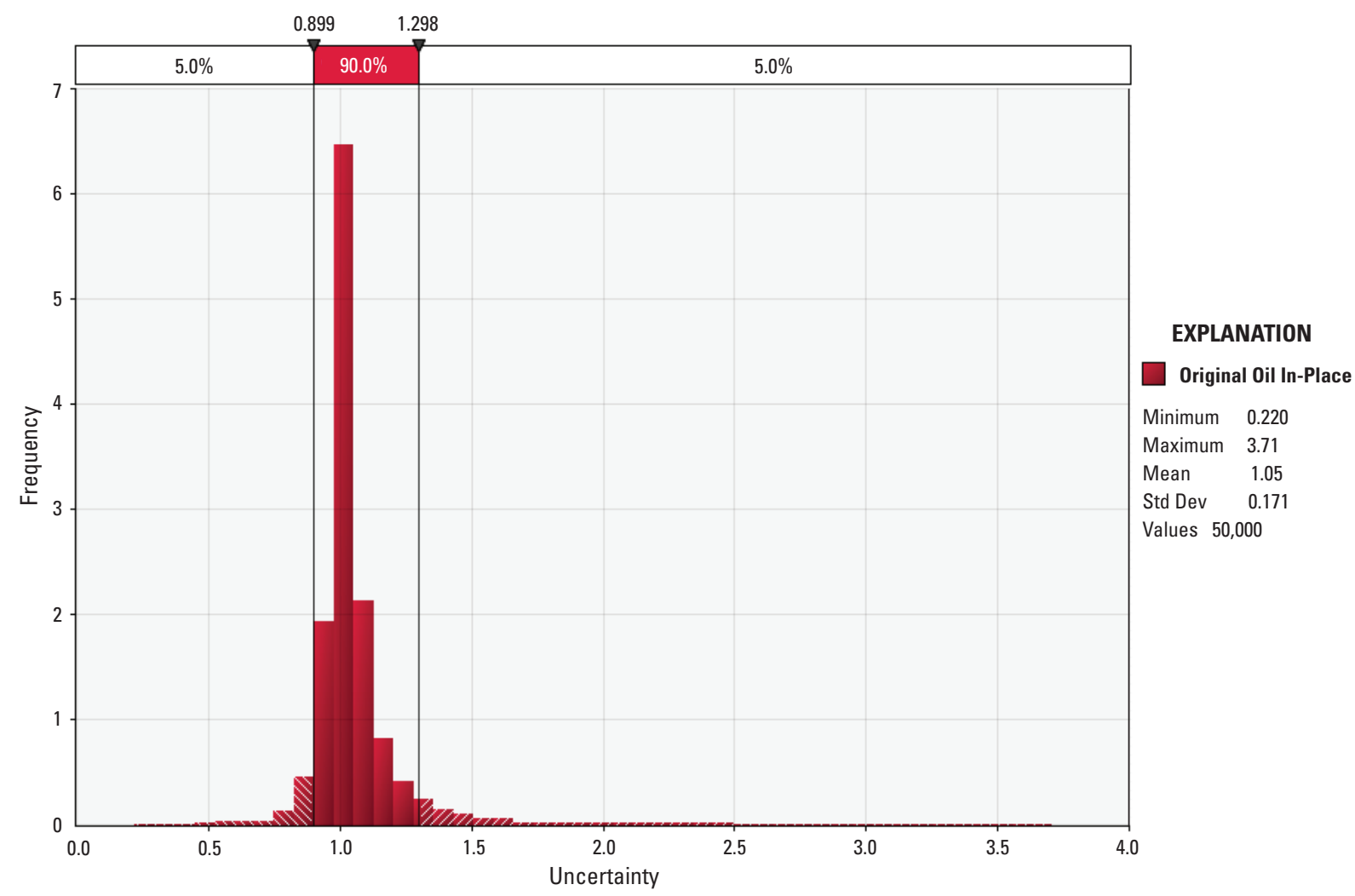

Figure 3. Bar chart showing the range of uncertainty of original oil in-place volumes for the 68 large U.S. oil accumulations that were individually analyzed in this study. The range is normalized to a central tendency of 1.0 and was applied to reported original in-place volumes for both oil and gas accumulations outside the United States. A value was randomly selected from this distribution during each Monte Carlo iteration and multiplied times the reported in-place volume of the accumulation, resulting in an in-place probability. (Std Dev, Standard Deviation; \%, percent)

field were sampled by Monte Carlo simulation to calculate an overall probability distribution (fig. 3). Complete dependency (perfect positive correlation where the correlation coefficient is 1.0) was assumed among the in-place volumes for all oil and gas fields.
Probability distributions of the recovery factors for each of the 1,467 oil fields and 347 of the gas fields outside of the United States were used to calculate an overall probability distribution of recoverability by Monte Carlo simulation (fig. 4). Complete independence (correlation coefficient of 0 ) was assumed among the fields because no two fields are developed in the same manner. 


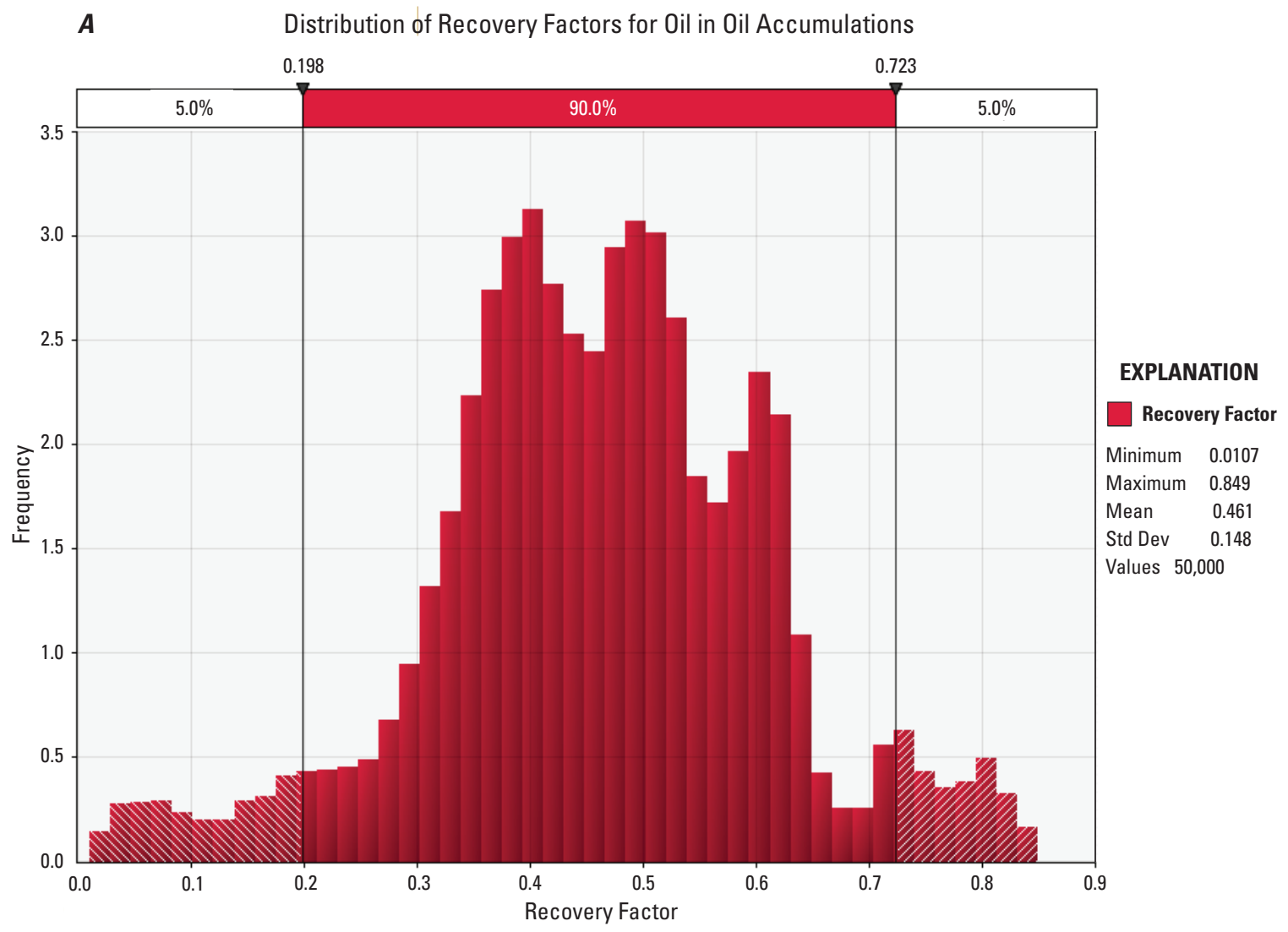

$\boldsymbol{B}$ Distribution of Recovery Factors for Gas in Gas Accumulations

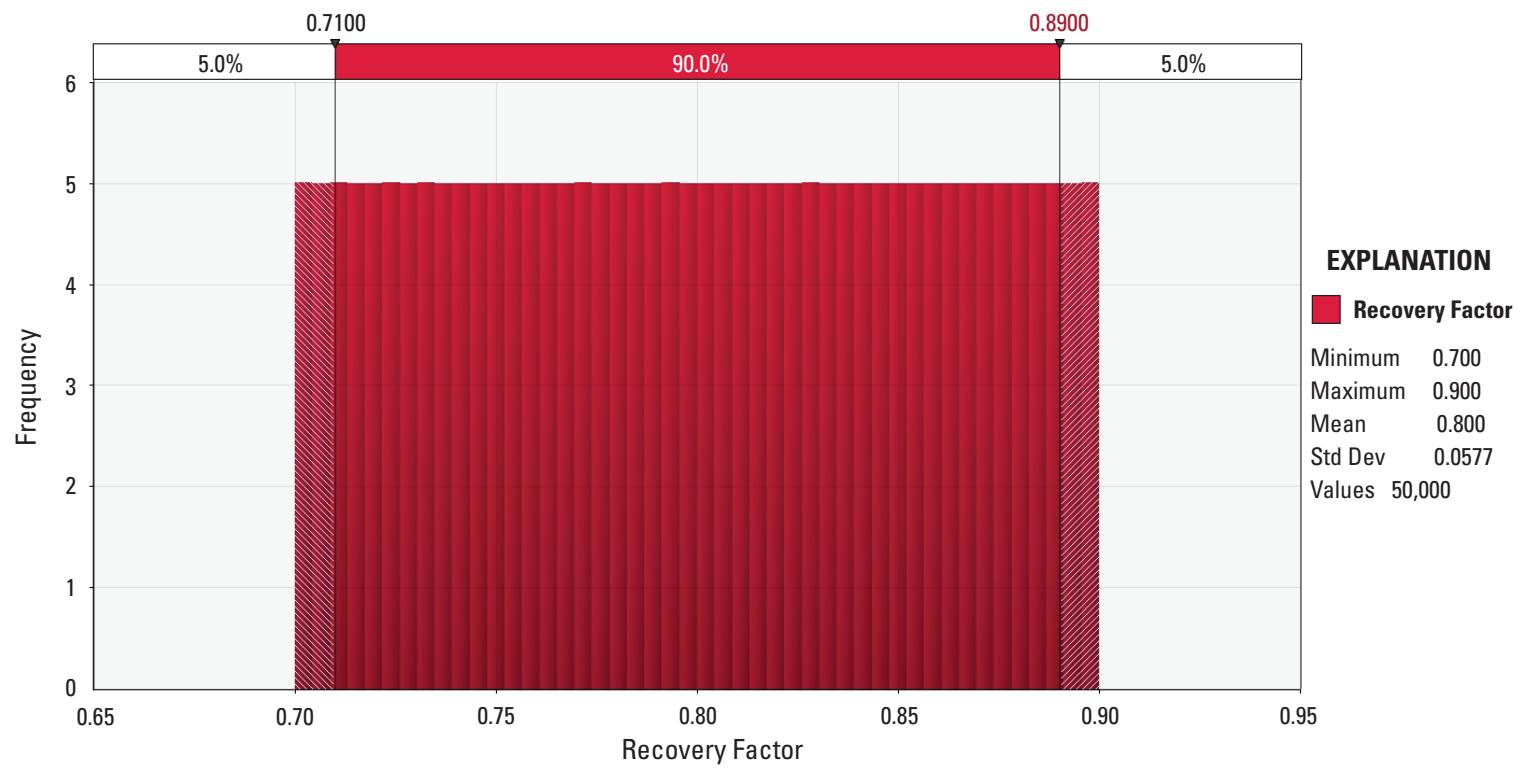

Figure 4. Bar charts showing the distribution of recovery factors used to calculate reserve growth in accumulations outside the United States. A. An empirical probability distribution of recovery factors of the 68 U.S. oil accumulations that were assessed using individual accumulation analysis. The recovery factors were used for oil accumulations outside of the United States. This distribution, based on U.S. accumulations, was used because a wide range of reservoirs, oil types, and degrees of development are represented. $B$. A uniform probability distribution of gasrecovery factors was applied to gas accumulations outside of the United States because reported recovery factors for gas accumulations outside of the United States varied widely and because only two U.S. gas accumulations were assessed using individual accumulation analysis. (Std Dev, Standard Deviation; \%, percent) 


\section{Assessment Results for Discovered Accumulations Outside of the United States}

Table 2 lists estimated volumes of technically recoverable, conventional oil and gas resources from reserve growth for large accumulations outside the United States. The estimated mean volumes of oil and gas are about 665 BBO of crude oil; 1,429 TCFG of natural gas [1,043 TCFG of associated and dissolved natural gas and 386 TCFG of nonassociated natural gas]; and 16 billion barrels of natural gas liquids
[ $-1 \mathrm{BBO}$ of natural gas liquids in oil accumulations and 17 $\mathrm{BBO}$ of total liquids in nonassociated gas accumulations] (Klett and others, 2012). Negative values indicate the possibility that the size of reported reserves could decrease rather than increase. The estimated amount of reserve growth is compared with volumes of cumulative production, remaining reserves, and undiscovered resources as shown on pie charts in figure 5.

Assuming that the amount of reserve growth is approximately proportional to original in-place volumes, this study estimated that about 80 percent of the potential reserve growth of the world outside the United States was accounted by this assessment; the other 20 percent was estimated to occur in accumulations with smaller in-place volumes (less than $500 \mathrm{MMBOE}$ ).

Table 2. Table of assessment results for discovered accumulations outside of the United States (technically recoverable, conventional petroleum resources) (Klett and others, 2012).

[BBOE, billion barrels of oil equivalent, BBO, billion barrels of oil; TCFG, trillion cubic feet of gas; BBNGL, billion barrels of natural gas liquids. For gas fields, all liquids are included under the natural gas liquids (NGL) category. Accum, accumulation. F95 denotes a 95-percent chance of at least the amount tabulated. Other fractiles are defined similary. Negative values indicated the possibility that reported reserves could decrease. Fractiles are not additive except under the assumption of perfect positive correlation. Gray shading indicates not applicable]

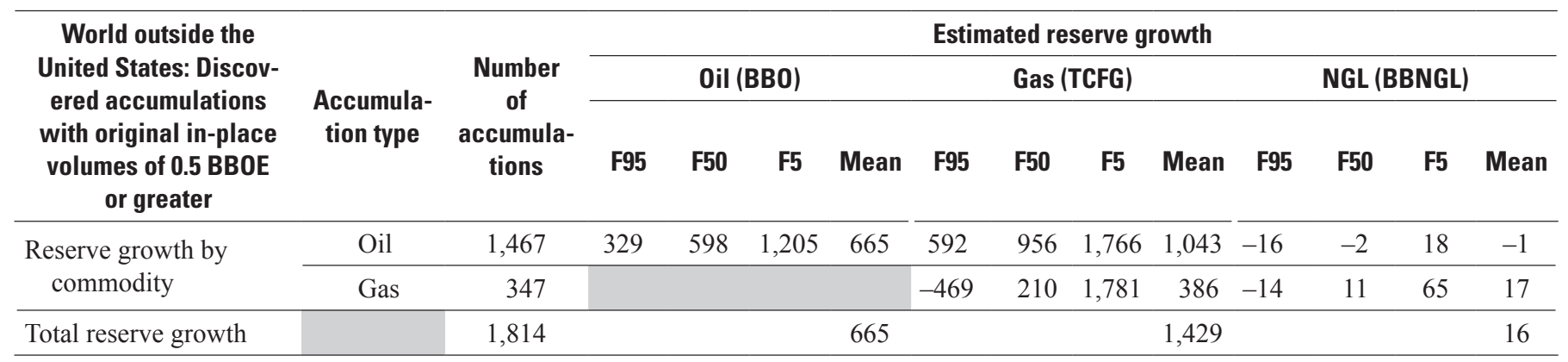

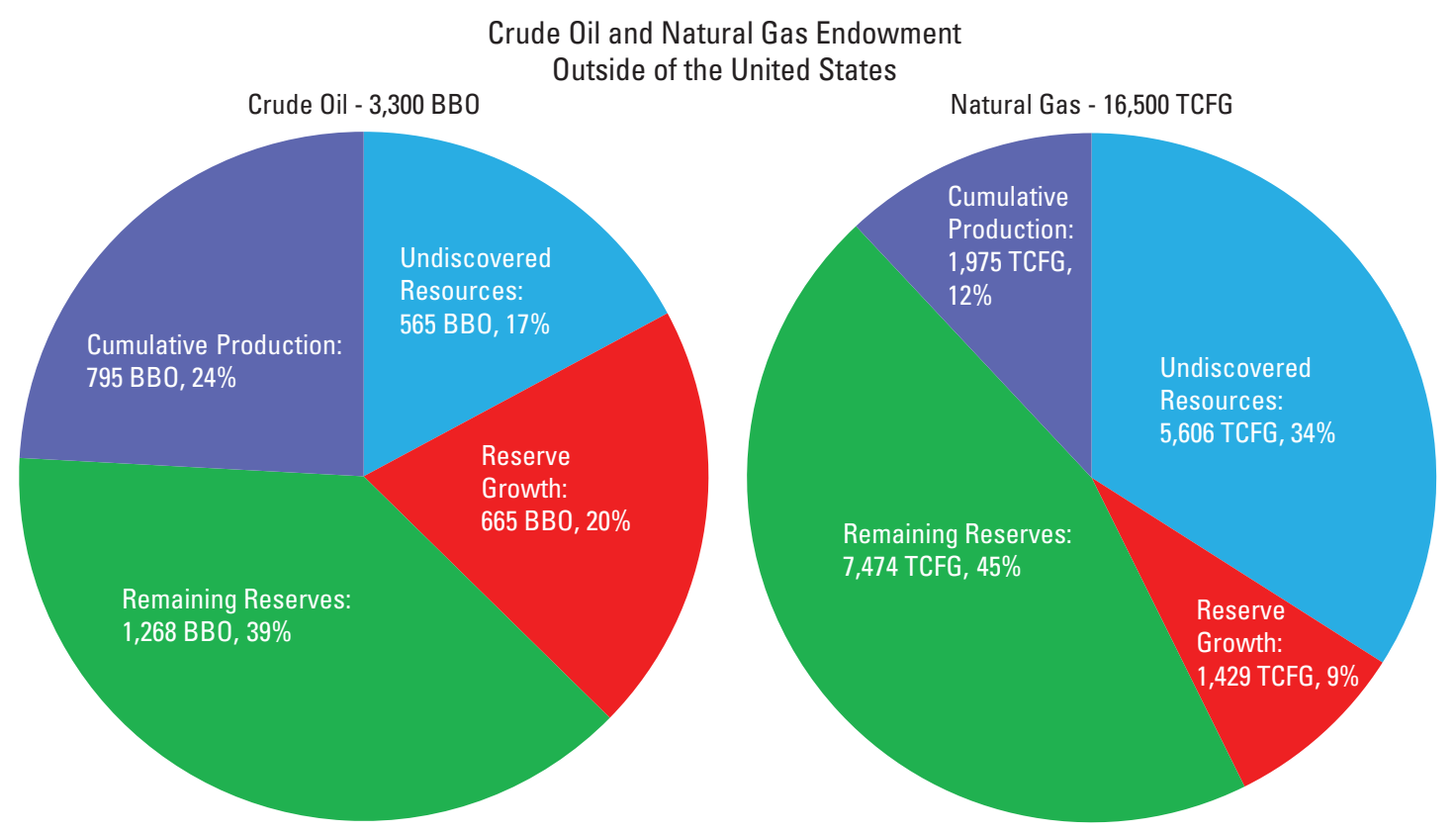

Figure 5. Circular (pie) diagrams showing crude oil and natural gas endowment outside of the United States. Data from IHS (2009) and Schenk (2012). Reserve growth was estimated by United States Geological Survey based on IHS (2009) in-place and recovery factor data. (BBO, billion barrels of oil; TCFG, trillion cubic feet of gas; \%, percent) 
Most of the world's reported original in-place and reserves volumes for oil in oil fields and gas in gas fields, outside the United States, are in 1,814 fields. Specifically, approximately 85 percent of the world's original in-place oil outside the United States is in 1,467 oil fields (about 9 percent of the total number of oil fields). Approximately 79 percent of the original in-place nonassociated gas is in 347 gas fields (about 3 percent of the total number of nonassociated gas fields).

\section{Future Research Directions}

Estimates of reserve growth of conventional oil and gas accumulations around the world can become more accurate as large, significant non-U.S. accumulations are individually analyzed. Assessments of non-U.S. accumulations by individual analyses outside of the United States have not yet been performed. An analysis of individual accumulations would increase the accuracy of reserve-growth estimates and reduce the uncertainty of the estimated volumes of conventional oil and gas accumulations both within and outside of the United States. Analysis of individual accumulations provides greater knowledge of the drivers of reserve growth. Furthermore, additional analyses and results can be compared to the recently released estimates of reserve growth outside of the United States in order to test the accuracy of the new reserve-growth methodology.

Additional research is required to calculate original inplace gas volumes and recovery efficiencies, in the absence of reported values, in order to provide better estimates of reserve growth in conventional gas accumulations. Reserve growth of gas accumulations was analyzed, but paucity of in-place gas volumes prevented individual analysis of many gas accumulations that significantly contributed to reserve growth. Our study found that much of the reserve growth in gas accumulations of the United States can be attributed to the addition of unconventional gas reservoirs in recent years. Conventional gas accumulations undergo some reserve growth, but growth is less significant than the reserve growth in oil accumulations or from unconventional reservoirs being developed along with previously discovered conventional gas reservoirs.

\section{Summary}

This 2012 study estimated reserve growth in large oil and gas accumulations having in-place volumes of $500 \mathrm{MMBOE}$ and greater. These accumulations are the largest contributors to reserve growth. Results of this study provide estimates of reserve growth for accumulations outside of the United States, accounting for much of the reserve growth worldwide. Results were reported along with the largest meaningful uncertainty. Individual analyses of geologic properties (for example, reservoir heterogeneity) and recovery factors of large U.S. accumulations provided analogs that allowed for more accurate estimates of these variables and their ranges for oil and gas accumulations outside of the United States.

\section{Acknowledgments}

The authors gratefully acknowledge the American Association of Petroleum Geologists Committee on Resource Evaluation (AAPG CORE) for reviewing the new USGS methodology, as well as their advice and guidance at the onset of this reserve-growth assessment project.

\section{References Cited}

Charpentier, R.R., and Cook, T.A., 2011, USGS methodology for assessing continuous petroleum resources: U.S. Geological Survey Open-File Report 2011-1167, 73 p., http://pubs. usgs.gov/of/2011/1167/.

Cook, T.A., 2013, Reserve growth of oil and gas fieldsInvestigations and applications: U.S. Geological Survey Scientific Investigations Report 2013-5063, 29 p., http:// pubs.usgs.gov/sir/2013/5063/.

IHS, 2009, International exploration and production database: Database available from Information Handling Services (IHS)15 Inverness Way East, D205, Englewood, Colo., 80112 .

Klett, T.R., 2005, United States Geological Survey's reservegrowth models and their implementation: Natural Resources Research, v. 14, no. 3, p. 249-264.

Klett, T.R., Attanasi, E.D., Charpentier, R.R., Cook, T.A., Freeman, P.A., Gautier, D.L., Le, P.A., Ryder, R.T., Schenk, C.J., Tennyson, M.E., and Verma, M.K. (U.S. Geological Survey Reserve Growth Assessment Team), 2011, New U.S. Geological Survey method for the assessment of reserve growth: U.S. Geological Survey Scientific Investigations Report 2011-5163, 9 p., http://pubs.usgs.gov/ $\operatorname{sir} / 2011 / 5163 /$.

Klett, T.R., Cook, T.A., Charpentier, R.R., Tennyson, M.E., Attanasi, E.D., Freeman, P.A., Ryder, R.T., Gautier, D.L., Verma, M.K., Le, P.A., and Schenk, C.J. (U.S. Geological Survey Reserve Growth Assessment Team), 2012, Assessment of potential additions to conventional oil and gas resources of the World (outside the United States) from reserve growth, 2012: U.S. Geological Survey Fact Sheet 2012-3052, 2 p., http://pubs.usgs.gov/fs/2012/3052/.

Schenk, C.J., 2012, An estimate of undiscovered conventional oil and gas resources of the world, 2012: U.S. Geological Survey Fact Sheet 2012-3042, 6 p., http://pubs.usgs.gov/ fs $/ 2012 / 3042 /$.

Schenk, C.J., and Pollastro, R.M., 2002, Natural gas production in the United States: U.S. Geological Survey Fact Sheet FS-113-01, 2 p., http://pubs.usgs.gov/fs/fs-0113-01/fs-011301.pdf. 
Schmoker, J.W., 1996, Method for assessing continuous-type (unconventional) hydrocarbon accumulations, in Gautier, D.L., Dolton, G.L., Takahashi, K.I., and Varnes, K.L., eds., 1995 National assessment of United States oil and gas

resources - Results, methodology, and supporting data: U.S. Geological Survey Digital Data Series DDS-30, Release 2 (CDROM).

Or visit the Central Energy Resources Science Center Web site at: http://energy.usgs.gov/

Box 25286

Denver, CO 80225

1-888-ASK-USGS 


\section{Appendix 1. Final Report of the AAPG CORE Subcommittee 8-11-09}

Final Report of the Sub-Committee for Growth-toKnown Reserves of the Committee on Resource Evaluation (CORE) of the American Association of Petroleum Geologists

\section{Introduction}

This final sub-committee report is a culmination of the work of the AAPG CORE and its sub-committee on Growthto-Known Reserves (GTK) in response to a 2006 request from the USGS Energy Resources Team. In that request, the USGS asked the CORE peer review and comment about the methods used to develop the Growth-to-Known (GTK) prediction factors for future resource assessments.

Members of the CORE initially met and reviewed the analysis with the Team in 2006/early 2007. During the course of the review, sub-committee recommendations about how this work and analysis might be performed were conveyed verbally to Survey personnel. At the 2007 Long Beach meeting, a summary report was compiled and reviewed by a quorum of the committee. Some members of the sub-committee met again with the Team on March 11-12, 2008. This meeting was in conjunction with the biennial Fourth Workshop on Reserve Growth conducted by the Team, led by Tim Klett. A draft report was submitted to the CORE at the 2008 San Antonio meeting. A second draft report was circulated prior to the 3-31-09 teleconference of CORE. Comments were received and a discussion of the draft was held.

These previous CORE and Team meetings identified that the key steps in the process of determining the GTK multiplication factors are:

1. Data source: North American data is the most lengthy and complete data set to develop and test predictive methodologies. The sources of these data are IHS, NRG Associates, and the EIA OGIFF.

2. The evaluation process should be clearly described.

3. Test the forecast accuracy and identify the forecast drivers.

4. Use abandoned fields as a benchmark.

5. Study a significant number of fields with all methods.

6. The use of stationary time series where the future $=$ the past.

7. Perform hind casting against the results of well characterized field studies.

\section{Status of USGS Energy Team GTK 2009}

Early in 2009, Tim Klett advised that the USGS GTK Assessment Project was proceeding as planned. In 2008, the Team published Chapter I of USGS Bull. 2172. The title of the report is Geologic Controls on the Growth of Petroleum Reserves by Fishman, Turner, Peterson, Dyman, and Cook. No other reports on Reserve Growth were published by the team this past year. Tim Klett also advised that several of his team members will be presenting their GTK work at the June 2009 Denver AAPG convention.

The Team will be using the NRG Associates 2008 Significant Oil and Gas Fields of the U.S. From this data base the Team will combine some NRG fields to "whole fields" where there exist boundary issues that create more than one data set for a named field. They will construct the reserve growth functions using the Lp-Norm Criterion (the renamed Monotone Least-Squares Method) and the Modified Arrington Methods. As reported in the summary of Chapter I, to add more precision to these statistical methods, the USGS Team investigated some of the geologic factors that affect oil field reserve growth. In this study they identified 10 U.S. formations that possess gross geologic differences as determined by environments of deposition. Further they defined various categories of reservoirs within these formations on other basis such as: porosity and permeability; source rocks; traps and seals; structural evolution; and postdepositional history. They concluded that "(oil) fields with low production variability have the potential for more predictable growth than fields with high production variability". They attribute this conclusion to reservoir heterogeneity.

Additionally, they will use Individual Field Analysis Method (based on several field studies in the San Joaquin Valley, California) on significant "outliers" (big fields). This method involves determining probabilistic estimates of inplace hydrocarbons combined with probabilistic estimates of recovery factor. From this estimate of ultimate recovery, they will subtract cumulative production. The remaining reserve estimate can be used to determine future reserve growth. New reserve growth functions will be developed by the above methods, tested, and if satisfactory, applied to the "outliers" of U.S. reservoirs in future assessments.

Also, the USGS Team plans to apply the above statistical and field analysis approach for future world assessments using the IHS International data base. 


\section{Discussion and Recommendations}

Key Steps 1 and 2; Data Source and Description of Methods; The sub-committee endorses the Team's use of NRG and IHS field data as the most complete available for historical growth. We think these data sets, in particular NRG in the U.S., will allow the development of the most detailed historical field growth functions by year and total field life to date. These are the data that most of the industry uses to study the growth of field reserves. With the NRG U.S. growth factors as a guide, the Team will use the IHS international reserve data, which grows more complete each year, for World Assessments.

The recent (2008) publication of Chapter I, USGS Bulletin 2172, together with the presentations to be given at this year's convention, and at planned biennial Workshops show that the process of developing reserve growth functions are constantly being refined. The methods are clearly described by the Team in these public presentations.

Key Steps 2, 4, and 6; Evaluation, Forecast, and Time Series; The sub-committee endorses the use of both the Lp Norm (ex-Monotone) and Modified Arrington Methods for the statistical development of the field growth functions for future assessments. These methods are based on construction of a discovery table by either discovery year or year since first production, and using the data bases to identify the field reserve increases through time. Both methods use this table to calculate an annual growth factor and a cumulative growth factor. The Modified Arrington method was used to develop functions in past U.S. and World assessments.

Additionally, the Team continues to refine the results of the forecast methodology by evaluating the geologic factors affecting reserve growth. In Bulletin 2172-I, they selected 10 U.S. formations to investigate the variation of reserve growth function in siliciclastic and carbonate reservoirs. The functions for these gross categories also were studied by introducing depositional setting, source rock, and post-depositional alteration. Further studies of this nature can only help bring more geologic insight to what has been mainly a statistical prediction.

The development of the growth functions should continue to use the most recent NRG data in the U.S. Some of the abandoned fields' growth functions while inactive are being used as calibration of the predictions. The Team will remove "continuous plays" in analyzing the growth of field reserves. These continuous accumulations will be treated separately. It is worth noting that the USGS has requested the CORE to review separately their continuous assessment methodology. That work is just commencing.
Key Step 3, Drivers; The sub-committee recommends the studies continue to identify the important drivers of growth. These drivers may be geologic, technologic, economic, or sociopolitical. Once the drivers have been identified, we suggested that the Team look at utilizing graphic presentation "tornado charts" to analyze the drivers and show their relative importance.

Key Step 5 Multiple Methods; The subcommittee endorses the use of statistical and field study methods on the big oil field "outliers". The analysis is based on studies of the large mature oil fields in the San Joaquin Basin. The method consists of an extensive field study that treats large fields as an assessment unit. In most mature petroleum provinces, the large or giant fields have the most volumetrically significant reserve growth. The reserve growth of several large fields will dominate the growth potential for the area or province. The field analysis involves acquiring the geologic characteristics of the field, information on the total resource in-place (OOIP), estimating how much of the oil will be recovered by all means, and comparing to known recoverable oil. The goal is to predict a range of increases in reserves based on the geology and future development technology. The production history plots are an excellent graphic to demonstrate field growth and relate cumulative production to OOIP. The cumulative plots could be extended for a forecast period by plotting the estimated growth calculated by the various methods. Like the estimates of OOIP, it would be a simple matter to place future time events on the graphic that might influence the shape of the extended creaming curve.

\section{Summary}

The sub-committee endorses the Energy Resources Science Center use of the statistical methods of the Lp Norm and Modified Arrington to develop field growth functions based on NRG Associates field data in future National and World Resource Assessments. Further, we endorse the continued refinement of the methods by the ongoing investigation of the effects of formation, reservoir type, and other factors at the reservoir level. Also, we support the use of field studies of the "big oil fields" to develop growth functions based on estimates of OOIP.

The members of the sub-committee wish to thank the Team for their co-operation during this review.

I wish to thank the members of the sub-committee for their comments on this report.

Lee B Backsen, coordinator

Sub-committee for Growth-to-Known Reserves, AAPG CORE committee 



\section{$\frac{\mathbb{2}}{3}$}

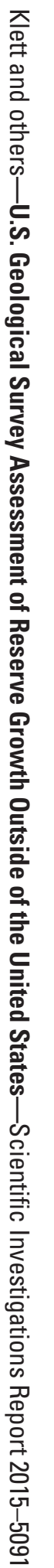

